\title{
"E o racismo no Vidigal?": reflexões sobre a promoção da igualdade racial orientadas pelo ensino da história e da matemática com recursos digitais
}

"What about the Racism in Vidigal?": Reflections on the Promotion of Racial Equality Guided by the Teaching of History and Mathematics Based on Digital Resources

Vitor Leandro de Souza* Danubia de Araujo Machado**

\section{Resumo}

$\mathrm{O}$ artigo relata uma experiência de ensino desenvolvida com a turma de $8^{\circ}$ ano do Ensino Fundamental, durante a Mostra Anual de Atividades promovida pelo Colégio Stella Maris, instituição confessional da rede privada do Rio de Janeiro. Os trabalhos desenvolvidos pelos alunos nos permitem criar espaços de discussão sobre a discriminação racial e as diferentes dimensões que perpassam a temática do racismo. Utilizamos conteúdos ministrados nas aulas de história e matemática sob uma perspectiva interdisciplinar e atenta a uma educação voltada à promoção da igualdade étnico-racial.

Palavras-chave: racismo; ensino de história e matemática; interdisciplinaridade.

\section{Abstract}

The article reports a teaching experience developed in a 8th grade Elementary School class during the Stella Maris School Annual Activity Show, a confessional religious institution of the private school network in Rio de Janeiro. With the works developed by the students we created spaces for discussion about racial discrimination and the different dimensions related to the theme of racism. We used topics taught in History and Mathematics classes in an interdisciplinary perspective, aiming to an education focused on the promotion of ethnic-racial equality.

Keywords: racism; History and Mathematics Teaching; interdisciplinarity.

\footnotetext{
* Doutorando em História Social da Cultura, Pontifícia Universidade Católica do Rio de Janeiro (PUC-RJ), Rio de Janeiro, RJ, Brasil. vitorleandro@id.uff.br

** Mestre em Modelagem Computacional, Laboratório Nacional de Computação Científica, Rio de Janeiro, RJ, Brasil. danubiad@gmail.com
} 
Tema sensível e urgente para a sociedade brasileira, as discussões sobre o racismo têm ocupado nosso cotidiano com frequência e despertado acaloradas discussões que adentram também o espaço escolar. São muito comuns situações e relatos conflituosos de alunos e professores permeados pela questão racial, impondo aos educadores a desafiante missão de enfrentamento do tema.

Este artigo tem como escopo apresentar as experiências de ensino desenvolvidas em uma turma do $8^{\circ}$ ano de Ensino Fundamental do Colégio Stella Maris, unidade escolar da rede privada situada na favela do Vidigal, Zona Sul carioca. As atividades realizadas no primeiro semestre de 2018 envolveram conteúdos das disciplinas História e Matemática e tiveram como culminância a Mostra de Atividades, promovida anualmente pela instituição. As ações realizadas nos permitiram criar espaços de reflexão sobre a discriminação racial e as diferentes dimensões que perpassam a temática do racismo na sociedade brasileira, particularmente na favela do Vidigal.

Mantido pela Congregação das Filhas de Jesus (FI), o Centro Popular de Educação e de Assistência Social Stella Maris atende, desde o ano de 2001, crianças e adolescentes, em sua maioria provenientes das comunidades do Vidigal e da Chácara do Céu. Com 935 matrículas da Educação Infantil ao Segundo Segmento do Ensino Fundamental, ${ }^{1}$ sua missão é "desenvolver as habilidades e competências através de aprendizagens contextualizadas ao tempo presente e a realidade atual" (Stella Maris, s. d.).

Essa atenção especial aos dilemas e demandas contemporâneos da comunidade escolar é um compromisso vivenciado particularmente pelos educadores do Colégio Stella Maris que, com esforços e criatividade, buscam ler a realidade atual associando ao dia a dia dos alunos, como observou e analisou Cristina Tepedino (2007, p. 90-95) em seu estudo sobre o cotidiano da instituição. Essa educação comprometida com as experiências reais dos alunos, conforme defendeu Freire (1996), possibilita que os educadores percebam e vivenciem diariamente as múltiplas dimensões do educar no contexto específico daquela favela carioca. Isso exige de cada educador estar sempre atento às dificuldades e aos anseios das crianças e adolescentes, assim como às complexas relações vivenciadas por eles no Vidigal, partindo para a realização de um trabalho de inserção social por meio de prática pedagógica que denominamos “educação em chaves positivas”. Ou seja, uma prática educacional preocupada 
em promover, em toda e qualquer situação, as múltiplas qualidades dos alunos, mediando reflexões e situações que lhes possibilitem o reconhecimento de sua história, de suas subvirtudes, seu modo de ser, estar e se relacionar com o mundo, e ainda valorizar as trocas de experiências que essa relação é capaz de proporcionar aos sujeitos.

Nesse sentido, unida às reflexões da Conferência Nacional dos Bispos do Brasil (CNBB) e dos diferentes movimentos sociais civis brasileiros para a Campanha da Fraternidade 2018 (CF18), ${ }^{2}$ a Equipe Diretiva propôs que a $5^{\mathrm{a}}$ Edição da Mostra Anual de Atividades tivesse como tema geral a "Superação da Violência" em seus mais diferentes aspectos, contando com subtemas que abordassem a "Violência Sexual", a "Violência doméstica" e a "Violência contra os imigrantes". Esses subtemas foram distribuídos entre as turmas da escola, da Educação Infantil até os anos finais do Ensino Fundamental, cabendo então às três turmas de $8^{\circ}$ ano apresentarem os resultados das reflexões sobre a superação do racismo, sob a perspectiva que compreende a temática como uma forma de extrema violência (Nunes, 2006).

Como o tema do racismo era comum às três turmas da unidade escolar, cada dupla de professores escolheu aspectos específicos da temática para serem tratados em sua respectiva turma. Buscando fugir de repetições na abordagem do trabalho, optamos pela estratégia de aplicação da temática em perspectiva "micro", valorizando a atitude de observação do alunado para o racismo como problema concreto em seu cotidiano e em sua comunidade.

Os trabalhos deveriam articular conteúdos programáticos ligados às disciplinas dos dois professores responsáveis na turma: História e Matemática, por entendermos a interdisciplinaridade como processo metodológico fundamental para que os sujeitos possam construir o conhecimento, apoiando-se, principalmente, nas suas relações com o contexto, com a realidade concreta em que os mesmos estão inseridos, inclusive sua cultura (Freire, 1987).

Nessa lógica, é fundamental que a interdisciplinaridade esteja em consonância com dois movimentos:

I - a reflexão e problematização da realidade em que se está inserido.

II - a sistematização dos conhecimentos integradamente. 
Consideramos ainda que a dialética de tais movimentos exige dos educadores visão integrada da realidade, além de domínio da própria área de formação. Também é necessário um desafiante esforço de apropriar-se das múltiplas possibilidades que os conceitos de sua área de formação articulam com outras ciências. Compreendemos, assim, que esse movimento não é das tarefas mais fáceis, sobretudo porque durante todo o processo formativo nós, educadores, somos estimulados por um movimento de especialização e isolamento constantes.

Nesse sentido, estamos de acordo com Gadotti (1999) ao considerar que a interdisciplinaridade tem como objetivo fundamental garantir a construção do conhecimento global, rompendo com as fronteiras aparentemente intransponíveis das disciplinas. E que assim, na mesma direção das afirmações de Fazenda (1979), mais que integrar conteúdos, cabe ao educador ir além, assumindo atitudes e posturas interdisciplinares, e que, fundamentalmente, esteja envolvido e comprometido com "a outra" área de conhecimento.

Daí nosso esforço e compromisso em efetivar essa prática sob o prisma interdisciplinar, compreendendo que tal dialética só tem a contribuir para uma educação integradora e globalizante (Pombo, 1994), que valorize os conteúdos programáticos dos componentes curriculares, que provoque os alunos a compreenderem criticamente a realidade em que vivem, e que eles sejam protagonistas de ações transformadoras dessa realidade (Bernstein, 1980).

Dividimos o relato da experiência em quatro partes, objetivando auxiliar na condução do percurso vivenciado por nós e pelos alunos anteriormente, ao longo da Mostra Anual de Atividades e posteriormente. A primeira delas é a apresentação discente, em que buscamos elaborar o Perfil da Turma (a); em seguida realizaremos a explanação das Etapas do Projeto $(b)$, em que apresentamos os conteúdos trabalhados durante as aulas com a turma, os quais nos ajudaram a elaborar ricas reflexões sobre a temática do racismo; prosseguimos o relato com a Avaliação (c) realizada após a atividade; e por fim, tecemos breves considerações finais $(d)$ sobre o trabalho.

\section{Perfil da turma}

A primeira atividade realizada foi a elaboração do perfil social dos alunos da turma do $8^{\circ}$ ano que acompanhamos para a Mostra de Atividades 
promovida anualmente pela instituição. Tal procedimento teve como objetivos possibilitar o autoconhecimento dos alunos em aspectos que serão abordados ao longo das atividades e demonstrar o modelo realizado posteriormente pelos próprios alunos no Vidigal, comunidade onde a grande maioria deles reside.

Em uma das aulas de História os alunos receberam um link da internet com um formulário contendo quatro perguntas que deveriam ser respondidas por cada um deles, como o Nome, a Idade, o Sexo e a Autodeclaração de cor/raça. Com base nas respostas dadas pela turma elaboramos o perfil do grupo.

Após a organização das respostas coletadas em sala de aula apresentamos os dados compilados aos alunos (Gráficos 1 e 2) e desenvolvemos noções básicas, de acordo com a metodologia proposta pelo Instituto Brasileiro de Geografia e Estatística (IBGE), de território (a sala), a questão de gênero (alunos e alunas) e a faixa etária discente (idade). Objetivamos, assim, orientar o processo de apropriação inicial da atividade de campo principal que foi realizada posteriormente pelos alunos e alunas nas ruas e vielas do Vidigal.

A composição discente total da turma é de 31; em sexo a composição declarada foi de 15 do masculino (48\%) e 16 do feminino (52\%). Quanto à faixa de idade da turma, a variação se dá entre 13 e 15 anos, sendo que a maioria (15 alunos e alunas) tinha 13 anos de idade na ocasião da resposta do formulário, outros 13 responderam ter 14 anos completos e, por fim, três alunos e alunas tinham 15 anos até o final do primeiro semestre de 2018.

Gráfico 1 - Faixa etária discente, $8^{\circ}$ Ano/Ensino Fundamental

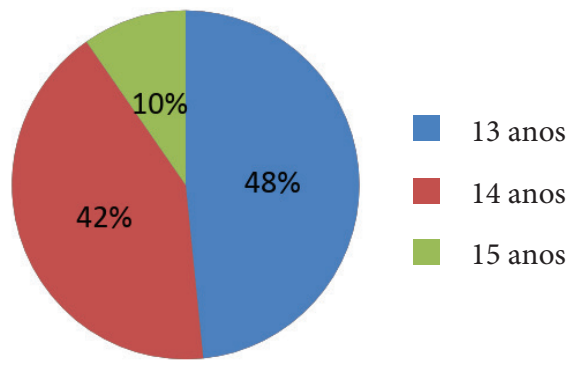

Quanto ao perfil racial, o critério utilizado foi o mesmo do IBGE, ou seja, o de autodeclaração (Petruccelli; Saboia, 2013). Considerando as 31 respostas 
fornecidas pelos discentes da turma, 45\% se autodeclararam de cor parda, outros $35 \%$ de cor branca, já os que se declararam da cor preta foram $16 \%$, e por fim, 3\% responderam identificar-se racialmente como "indígena".

Gráfico 2 - Autodeclaração cor/raça discente, $8^{\circ}$ Ano/Ensino Fundamental

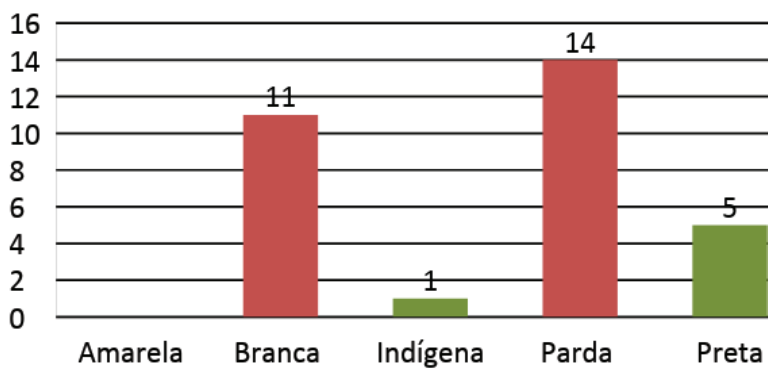

Nessa conversa prévia, além de explanar os dados do levantamento realizado na turma, explicamos a importância dos censos para o conhecimento da sociedade brasileira - sua composição, transformações e demandas -, assim como a formulação e implantação de políticas públicas direcionadas às necessidades dos sujeitos representados nos levantamentos. Esses dados favorecem a construção de reflexões sobre a diversidade populacional brasileira, suas demandas e a importância de instituições que possibilitem o atendimento dos direitos fundamentais para a construção da cidadania (Tavares, 2007), para a promoção de direitos humanos (Garretón, 1999), que contribuam para a visão do Brasil como um país plural e para atitudes e ações calcadas no respeito às diferenças socioculturais (Brasil, 2010, p. 7).

\section{ETAPAS DO PROJETO}

O projeto que a turma apresentou na Mostra de Atividade do Colégio Stella Maris buscou compreender a questão do racismo no Vidigal. Assim, como estratégia, além de utilizarmos a metodologia semelhante àquela trabalhada em sala de aula para levantar o perfil dos alunos e alunas da turma, articulamos conteúdos próprios do $8^{\circ}$ ano do Ensino Fundamental referentes à História e à Matemática. Sendo a Mostra Anual de Atividades o momento de 
culminância do projeto realizado com a turma, organizamos as atividades como no exposto Quadro 1.

Quadro 1 - Desenvolvimento das etapas do projeto

\begin{tabular}{|c|c|c|c|}
\hline $\begin{array}{c}1^{\circ} \text { Momento } \\
\text { Teórico }\end{array}$ & $\begin{array}{c}2^{\circ} \text { Momento } \\
\text { Empírico }\end{array}$ & $\begin{array}{c}3^{\circ} \text { Momento } \\
\text { Apropriação }\end{array}$ & $\begin{array}{c}4^{\circ} \text { Momento } \\
\text { Culminância }\end{array}$ \\
\hline $\begin{array}{c}\text { Aulas expositivas } \\
\text { e dialógicas }\end{array}$ & $\begin{array}{c}\text { Coleta de } \\
\text { dados }\end{array}$ & $\begin{array}{c}\text { Sistematização e } \\
\text { produção de materiais }\end{array}$ & $\begin{array}{c}\text { Apresentação para a } \\
\text { comunidade escolar }\end{array}$ \\
\hline
\end{tabular}

\section{Momento: Teórico}

Além da explanação sobre a metodologia, nas aulas expositivas, foram trabalhados os conteúdos da disciplina História relacionados à questão escravista brasileira no século XIX e como os africanos trouxeram um importante legado na formação sociocultural brasileira. Nesse sentido, aulas sobre os movimentos de contestação da escravidão e do poder central valorizaram o protagonismo de personagens negros e os processos históricos de sua exclusão na sociedade brasileira, como as análises sobre os processos históricos e as lutas contra a exclusão do negro na sociedade brasileira do Pós-Abolição.

Ao refletirmos em aulas sobre o escravismo no Brasil, buscamos mostrar a importância dos africanos para a formação sociocultural da identidade brasileira, e como os povos que foram aqui desumanamente escravizados trouxeram consigo sua cultura, arte e religiosidade, integrando-se à sociedade colonial e imperial e realizando, dinamicamente, profunda contribuição para essa nova sociedade que se estava construindo aqui.

Outro aspecto estudado se relacionou com a força do pensamento cultural no período. Com isso, tomamos o darwinismo social como exemplo de ferramenta primordial para a consolidação e institucionalização do racismo no Mundo Contemporâneo e, em particular, no Brasil. Também refletimos sobre o racismo como herança social brasileira presente ainda nos dias atuais, que se materializa em nosso cotidiano por meio de políticas públicas que operam na manutenção da exclusão e, também, em ações individuais disseminadas pelo preconceito racial, inclusive no ambiente escolar. 
Nas aulas propostas, percebemos como tais discussões foram assimiladas pelo alunado e as tensões próprias de um tema tão sensível como o racismo ocupa um lugar central no cotidiano de cada aluno e aluna. Evidencia-se, também, como a elaboração do discurso civilizatório eurocêntrico, fortemente racista, que se mantém ainda hoje, exige de nós, educadores, uma prática educativa de valorização da forte influência da cultura africana como matriz fundamental nos traços culturais da população brasileira.

Inteiramente vinculado à história de opressão e de violação de direitos decorrentes da escravidão, o norteador das aulas expositivas preparatórias para a elaboração do material da Mostra Anual de Atividades foi a premissa de que "o racismo vem sendo recriado e realimentado ao longo de toda a nossa história. É, portanto, impraticável desvincular as desigualdades observadas atualmente dos quase quatro séculos de escravismo que a geração atual herdou" (Brasil, 2001). Ou seja, a marginalização enraizada em nossa sociedade tem bases muito sólidas na história escravista brasileira, sendo impossível desvincular os complexos problemas sociais contemporâneos da herança decorrente dos impactos provocados pelo processo civilizatório desigual e excludente a que foram submetidos os povos indígenas nativos e as populações negras originárias da África nas Américas e, mais particularmente, no Brasil.

Conscientes da urgência da aplicação de uma prática pedagógica voltada à igualdade nas relações étnico-raciais, buscamos reeducar primeiramente nossos olhares sobre os conteúdos e lançamos o compromisso da aplicação de uma educação que lute contra o racismo, tão presente no nosso cotidiano escolar (Gomes, 2011).

Entendemos que promover a igualdade étnico-racial a partir dos conteúdos é um exercício que demanda paciência e atenção para trazer aos alunos a historicidade das condições dos negros no Brasil e as lutas que essas reflexões possibilitam. Ainda que em grande medida sejam óbvias as condições de marginalidade a que os negros foram historicamente submetidos, "como é frequente acontecer com tudo o que é óbvio, [...] acaba sendo esquecido ou ocultando, na sua aparente simplicidade, problemas que escapam a nossa atenção. E esse esquecimento, essa ocultação, acabam por neutralizar os efeitos da escola no processo de democratização" (Saviani, 1991, p. 23). É, portanto, essencial o comprometimento por parte dos professores na elaboração de estratégias que contribuam no pensamento da questão racial para além da especificidade 
negra, mas antes de tudo pensar que essa é uma questão que envolve também os brancos. Afinal, o combate ao racismo e a qualquer outro preconceito traz ganhos para toda a sociedade.

Quanto aos conteúdos de Matemática, visto que os alunos trabalharam com coleta de dados, um dos tópicos da disciplina foi o tratamento das informações reunidas pelos alunos. Nesse conteúdo o objetivo foi ler, organizar e representar dados por meio de gráficos, buscando a melhor forma para representar o conteúdo. O outro tópico trabalhado foi de Porcentagem, na qual os alunos precisaram entender o funcionamento e a participação ativa na apresentação de dados comparativos e organizacionais, no campo da Estatística.

Atentando para que a turma tivesse visão ampla e integrada dos conteúdos de História e Matemática, buscamos articular os conteúdos trabalhados, reunidos às discussões e debates mediados por nós, professores, sobre a realidade social brasileira, analisando como tais dados estatísticos são ferramentas favoráveis na problematização do desenho social do Brasil.

\section{$2^{\circ}$ Momento: Empírico}

A proposta de ação discente em campo, a favela do Vidigal, consistiu na aplicação de questionário entre os moradores da comunidade. As questões utilizadas foram elaboradas com ativa participação dos alunos a partir de discussões que foram mediadas por nós, professores, com o devido cuidado para não perder de vista o objetivo principal: levar os alunos e a comunidade escolar a refletirem sobre a questão da violência racial no Vidigal, articulando tal situação vivida na favela da Zona Sul carioca com a realidade macro do Brasil, salientando possíveis proximidades e distanciamentos e buscando reconhecer as diferentes formas de vivência do racismo pelos moradores, dentro da comunidade e/ou fora dela. Por fim, buscamos compreender as estratégias e esforços realizados cotidianamente por esses sujeitos no intento da sua superação.

Dessa maneira, após as discussões com os alunos para a pesquisa indagamos os entrevistados sobre a experiência individual acerca de "ter vivido ou presenciado alguma situação motivada pelo racismo". Nosso interesse com a amostragem possibilitada pela pesquisa consistiu em elaborar um panorama sobre o perfil da população residente no Vidigal, assim como compreender os modos pelos quais o racismo se materializa cotidianamente na vida dessa população. 
Alguns alunos ficaram responsáveis por realizar as entrevistas, divididos em grupos, e cada "entrevistador" deveria apresentar entre três e cinco formulários com entrevistas, de modo a realizarmos um levantamento total de cem moradores da favela do Vidigal. Nesse primeiro momento o levantamento tinha de ser realizado, obrigatoriamente, em formulário de papel. E cada "entrevistador" não poderia entrevistar moradores da mesma residência, devendo haver também, entre os entrevistados, diferenças de faixa etária. Assim, possibilitamos maior pluralidade na amostragem, além de estimularmos os alunos a priorizarem múltiplas conexões, ou seja, redes de relações diferentes daquelas em que os "entrevistadores” estão inseridos ou habituados a participar.

Compreendemos como elemento natural a insegurança provocada pela realização de atividades que nos tiram de nossa zona de conforto, mas, como afirma Saviani (2008, p. 13), "a educação diz respeito, de um lado, à identificação dos elementos culturais que precisam ser assimilados pelos indivíduos da espécie humana para que eles se tornem humanos e, de outro lado e concomitantemente, à descoberta das formas mais adequadas para atingir esse objetivo".

Nosso empenho como profissionais comprometidos com a educação consiste portanto em, de maneira engajada, buscar uma prática renovadora, sempre atenta às demandas e aspirações dos nossos alunos. E tal prática deve estar apoiada e inserida nas múltiplas formas de ensinar, buscando o desenvolvimento discente global.

\section{$3^{\circ}$ Momento: Apropriação}

Finalizado o processo de coleta de dados, seguimos para o tratamento das informações. No laboratório de informática do Colégio Stella Maris os alunos realizaram a sistematização das respostas dadas pelos entrevistados. Criou-se um formulário no Google Docs (ver Anexo I), a ser alimentado pelos alunos com as informações obtidas na pesquisa de campo. Esse processo foi importante para que cada aluno se apropriasse dos recursos tecnológicos, adquirindo, assim, um conhecimento mais amplo nessa área. Além disso, os alunos puderam perceber que a coleta de dados gera resultados importantes acerca de determinado assunto, colaborando para dados estatísticos da sua comunidade.

Atentos ao atual momento histórico, compreendemos que as novas tecnologias estão muito presentes na vida cotidiana de todos, e que elas são 
ferramentas importantes para o processo de ensino/aprendizagem. Eficientes nas iniciativas de diversificação da complexa tarefa do "ensinar-aprender", as novas tecnologias valorizam a produção de conhecimentos, proporcionando a ampliação na interação entre nós, professores, e os alunos.

Durante a aula de História, com resultados da pesquisa já em mãos e organizados automaticamente pelo site, contando até mesmo com gráficos e tabelas variadas, conversamos e partimos para a análise dos dados, de modo a compreendermos como eles refletiam os números do censo nacional, e como de alguma maneira se aproximavam do levantamento realizado previamente na elaboração do perfil da turma.

Considerando o universo de cem moradores entrevistados, $63 \%$ eram mulheres e $37 \%$ homens. Em comparação com os dados relativos à cidade, percebemos que essa tendência de um número maior de mulheres que de homens se confirmou. Ainda que o levantamento realizado pelos estudantes considere a amostragem, acreditamos que o maior número de mulheres pode, de certa maneira, ter influenciado nos números. A explicação dada por um "entrevistador" sobre a predominância de mulheres diz respeito a um caráter mais subjetivo, que se refere ao acolhimento e disponibilidade das mulheres em participarem da pesquisa e atenderem às demandas dos alunos durante a aplicação dos questionários.

Entretanto, nessa direção estão os dados apresentados pelo censo brasileiro e analisados por Barbara Cobo $(2014)^{3}$ mostrando que as mulheres, além de serem a maioria no cenário populacional geral do Brasil, ainda respondem significativamente pelos números da economia, da atividade comercial e sustento das casas e famílias. Mesmo numa sociedade tão desigual, em que a questão da (des)igualdade de gênero foi particularmente polemizada e assumida como ponto chave no debate político-eleitoral, o protagonismo da mulher - demonstrado nos números e presenciado por todos nós no cotidiano - não deve ser ignorado ou menosprezado pelos componentes curriculares.

Quanto ao item Idade dos entrevistados, os números foram bem variados, com idades que iam dos 12 aos 90 anos. A concentração etária dos entrevistados (30\%) está na faixa de 20 a 29 anos; outros $21 \%$ dos que responderam tinham entre 30 e 39 anos; $28 \%$ entre 40 e 49 anos; $12 \%$ tinham entre 12 e 19 anos, e, por fim, $9 \%$ responderam ter entre 50 e 90 anos. Esses números refletem bem 
a pirâmide etária apresentada pelo Instituto Brasileiro de Geografia e Estatística (Brasil, 2010), ${ }^{4}$ em que a mesma tendência se apresenta.

Para o item religião, o levantamento realizado pelos alunos no Vidigal assemelhava-se aos números da cidade obtidos no recenseamento nacional. A maior parte dos entrevistados do Vidigal (58\%) declarou-se Católica, já 31\% responderam ser Evangélicos, outros 2\% declararam-se da Umbanda e 9\% responderam ter Outras religiões.

Quanto a Cor, cruzamos os dados levantados pelos alunos no Vidigal com os números apresentados pelo panorama divulgado pelo IBGE para a cidade do Rio de Janeiro, relativos ao ano de 2010. A tendência encontrada pelos alunos foi semelhante àquela mostrada pelo Censo para o município carioca. Diante dos dados, um dos alunos observou um problema: a dificuldade de alguns entrevistados em reconhecer-se como parte da população preta.

Diante das observações do aluno, pudemos refletir sobre as categorias de análise relativas a Cor adotadas pelo IBGE, que em sua maioria não vêm correspondendo aos termos utilizados pela população. Isso indica que os percentuais da categoria parda certamente não dão conta de refletir a realidade da população seja no levantamento do IBGE, seja na pesquisa por amostragem realizada pelos alunos. Lembremos que esse termo apresenta-se como uma posição social intermediária da população brasileira, sendo percebida como atenuante das diferenças desiguais e injustas da polaridade branca e preta.

Gráfico 3 - Autodeclaração cor/raça - Pesquisa realizada no Vidigal

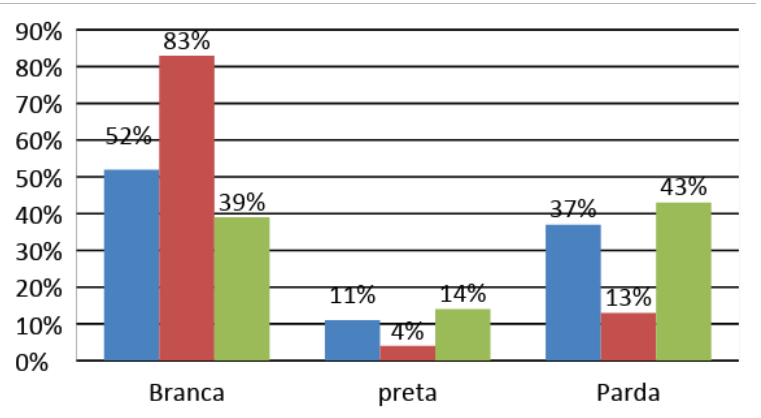

Rio de Janeiro (Município) $\quad$ Zona Sul RJ $\square$ Vidigal 
O último recenseamento nacional, realizado em 2010, mostrou que a população brasileira, de 191 milhões, declarou ser pela primeira vez em sua maioria $(50,7 \%)$ parda ou preta - respectivamente $47,7 \%$ e $7,6 \%$-, em um evidente processo de "enegrecimento". Para termos uma ideia, no Censo de 2000 a população que se declarou parda foi de $38,9 \%$, e preta, $6,1 \%$; contra $53,4 \%$ da opção branca. ${ }^{5}$ Mas como podemos explicar esse movimento de "enegrecimento" da população apresentado no último recenseamento?

Não há dúvida de que para uma parcela significativa da população brasileira, inclinada a valorizar traços fenotípicos brancos, a revalorização dos perfis e o reconhecimento que tal ideário eurocêntrico é inatingível - além de perpetuar a violência com a negação constante de suas origens - constituem ação libertadora de uma espécie de auto-opressão agressiva e cotidiana, embebida na percepção de pertencimento racial a determinado grupo sem querer a ele pertencer. Como em um quebra-cabeça em que as peças não se encaixam nas demais, esse conjunto gerado de maneira forçada jamais poderia formar a verdadeira imagem com perfeição.

Alessandro Santos e Saulo Fernandes observaram que:

É pela inscrição do sujeito num grupo de pertencimento que se torna possível participar da identidade coletiva e social que no grupo se processa. Desse modo, a identidade coletiva e social expressa um campo de disputa entre grupos, implicando relações de poder que produzem marcadores sociais de diferenciação e embates, como por exemplo, gênero e raça-etnia. Trata-se de marcadores da diferença que não funcionam de forma isolada, agindo uns sobre os outros e estabelecendo relações sistêmicas e assimétricas, devendo ser compreendido em sua interseccionalidade e como fruto de determinantes históricos e sociais que constituem um lugar e um tempo no qual o sujeito produz sua singularidade e experiências. (Santos; Fernandes, 2016, p. 262-263)

Portanto, essa revalorização dos elementos da cultura negra e a crescente autodeclaração "enegrecida" - expressa pelo número, cada vez mais elevado, de entrevistados assumindo-se como preto e pardo - estão fortemente vinculadas às lutas dos movimentos negros, que ao longo da história pressionaram para que tivessem seus direitos respeitados e fossem incluídos como cidadãos plenos na sociedade brasileira. Para isso contribuíram as políticas públicas voltadas para a população negra, como as ações afirmativas direcionadas aos 
negros e negras, e, ainda, as iniciativas ligadas diretamente ao campo educacional, como a implementação da Lei 10.639/2003, que colaboraram para o reconhecimento das inúmeras contribuições ativas dos povos africanos para o processo de formação identitária e cultural dos brasileiros.

O enegrecimento pode ser notado no cotidiano simples, porém extremamente representativo, do número cada vez maior de pretas e pretos que assumem sua identidade nos cabelos crespos, desfilam pelas ruas com seus turbantes e com sorriso no rosto, têm orgulho de sua origem e das lutas de seus antepassados. Para aquela turma de $8^{\circ}$ ano do Ensino Fundamental, em que a grande maioria é residente da favela do Vidigal, ainda que fossem negros e negras, mesmo não se identificando como tal, algo começava a ganhar um sentido diferente. Minimamente suscitava reflexões sobre o pertencimento racial e os esforços de tantos homens e mulheres em manter vivas suas tradições, direitos e cidadania.

Tendo se apropriado das informações e após conversarmos sobre elas, o passo seguinte exigiu que a turma elaborasse estratégias de apresentação dos resultados obtidos para a comunidade escolar. Buscamos nessa etapa da atividade valorizar a aplicação de ideias que visassem trabalhar com o concreto na apresentação dos dados estatísticos, e que prioritariamente fossem utilizados materiais de baixo custo, trazidos de casa pelos próprios alunos.

\section{$4^{\circ}$ Momento: Culminância}

Uma das preocupações da Equipe Diretiva é que a Mostra Anual de Atividades seja um momento no qual as portas da unidade escolar estejam abertas para as famílias e a comunidade em geral, por isso o evento é realizado em um sábado.

O ápice dos trabalhos realizados pelas turmas é, portanto, a apresentação dos resultados para a comunidade escolar. A dinâmica buscou demonstrar a concretização dos saberes discutidos ao longo de todo o processo. Esse formato evidencia o anseio da instituição em constituir-se como um espaço escolar cidadão e democrático. Esse é, portanto, um dia em que os alunos demonstram o seu protagonismo frente ao processo de ensino/aprendizagem, inserem-se como sujeitos na construção ativa e transmissão dos mais diferentes saberes. 
Realiza-se um processo intenso de trocas, em que os valores humanísticos e da cidadania se fazem fortemente presentes para toda a comunidade escolar.

A semana que antecedeu o evento foi dedicada à preparação dos materiais que seriam expostos ao público. Atendendo a uma educação de preservação dos recursos naturais e do meio ambiente, nós professores estimulamos a turma a investir na reutilização da maior parte dos materiais usados para a construção dos trabalhos a serem apresentados, priorizando o uso de embalagens plásticas descartáveis, a reutilização de papéis e de qualquer outro tipo de material que simplesmente seria descartado no lixo.

Na véspera do evento, o dia foi de imersão total das turmas nas atividades. Ao longo da manhã, os alunos concluíram a confecção dos materiais que seriam utilizados na exposição e fizeram uma apresentação prévia do material, numa espécie de ensaio geral onde dúvidas e orientações gerais puderam ser discutidas e solucionadas. Os alunos puderam ainda revisar os resultados da pesquisa realizada com os moradores do Vidigal e, após os ajustes nos dados, sanar as últimas dúvidas e possíveis questionamentos sobre a metodologia proposta e os resultados.

Separados em grupos, os alunos ficaram responsáveis pela construção e apresentação de seu resultado. Para que não fosse algo cansativo para o visitante, idealizamos informações muito diretas e objetivas. Os resultados compilados foram exibidos em "gráficos sólidos", como estratégia de dinamização das apresentações, além de enriquecê-las esteticamente, pois não poderíamos perder de vista que aquela apresentação reuniria grande parcela da comunidade do Vidigal.

Por fim, nós professores mediamos uma espécie de "visita simulada", em que fizemos perguntas plausíveis aos alunos sobre os resultados do levantamento realizado por eles e ouvimos as respostas, comentamos e explicamos. Tratou-se de um exercício coletivo de reflexão, construção do conhecimento, e de ajustes finais para o dia da apresentação.

Chegada a $5^{\circ}$ Mostra Anual de Atividades, o pátio da escola contava com grande número de visitantes: familiares, ex-alunos e moradores do Vidigal estavam ansiosos para o início do evento. Uma abertura oficial, de forma bem dinâmica, reuniu convidados, alunos, professores e funcionários do Colégio, para apresentações artísticas e musicais seguidas de recitação de poesias e 
explicação do tema motivador do projeto, sendo então as exposições dos trabalhos das turmas finalmente abertas ao público geral.

$\mathrm{Na}$ sala da turma de $8^{\circ}$ ano foram montados oito módulos, cada um deles contando com 3 ou 4 alunos que se revezaram ao longo do evento, cuja duração foi de cerca de 4 horas. Um dos esforços ao longo do dia consistiu em valorizar as intensas trocas entre os visitantes e os dados apresentados, mediante um exercício de escuta e reflexão sobre a problemática do racismo como violência vivenciada e praticada na/pela sociedade brasileira. Porém, de maneira muito particular, nosso foco estava direcionado a compreender e refletir sobre como a prática criminosa do racismo é vivida pelos moradores da favela do Vidigal, ou seja, o convite que fazíamos para os visitantes era de um olhar para si, para seu cotidiano, enfim, para seu contexto social representados naqueles dados.

Os módulos foram dispostos na Mostra Anual de Atividades desta maneira:

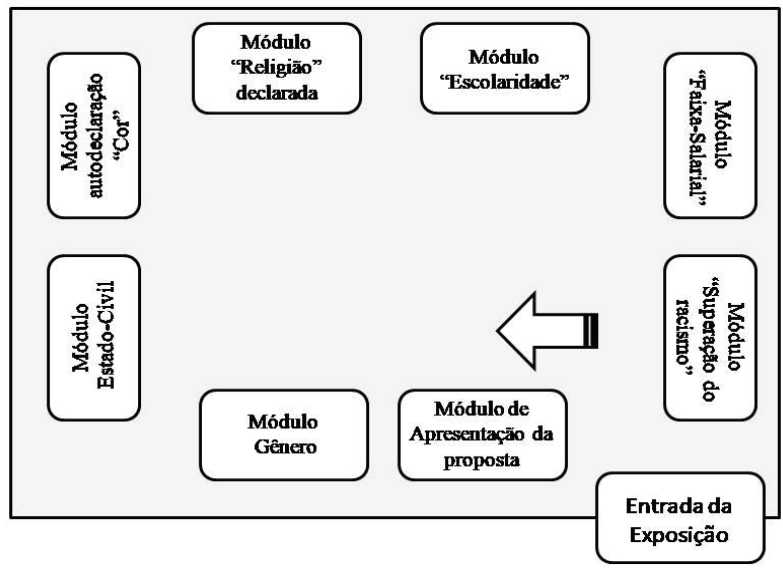

$\mathrm{Na}$ "Entrada da Exposição" os visitantes eram incentivados pelos alunos a visitarem os módulos da exposição produzida por eles. Após ingressar na sala, o visitante era conduzido para o "Módulo de Apresentação da Proposta”, que representava a favela do Vidigal por uma maquete e conduzia o visitante a responder sobre a existência do racismo na comunidade.

$\mathrm{Na}$ apresentação introdutória dos alunos explicou-se aos visitantes o método usado nas entrevistas e, principalmente, que as informações dos demais módulos estavam relacionadas às respostas dadas pelos moradores do Vidigal nas entrevistas colhidas previamente. 
Figura 1 - Módulo de Apresentação da proposta

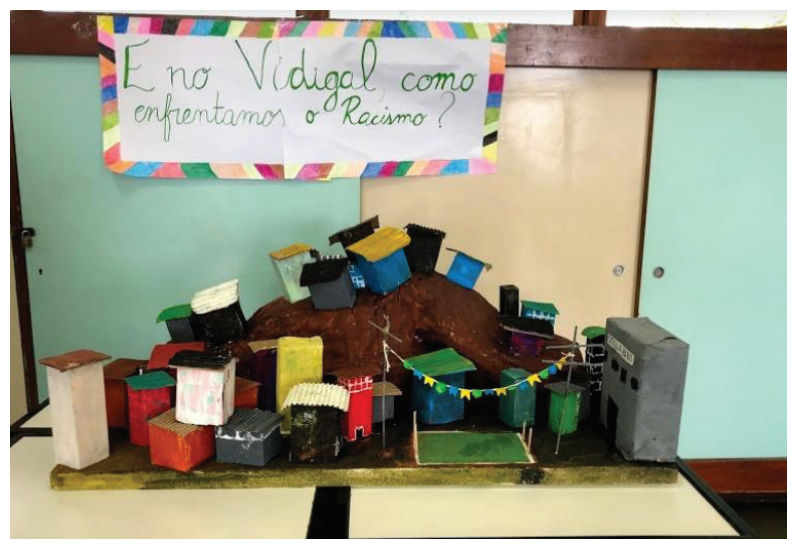

Fonte: acervo pessoal.

Os módulos permitiram aos visitantes compreenderem o panorama social dos moradores do Vidigal no que tange às questões de sexo, estado civil, cor/ raça, faixa salarial, religião e nível de escolaridade. Permitiu-se, assim, uma reflexão sobre o quanto esses números do levantamento realizado pelos alunos traduzem uma realidade muitas vezes não problematizada e/ou percebida pelos próprios moradores da comunidade.

\section{Figura 2 - Módulo Gênero}

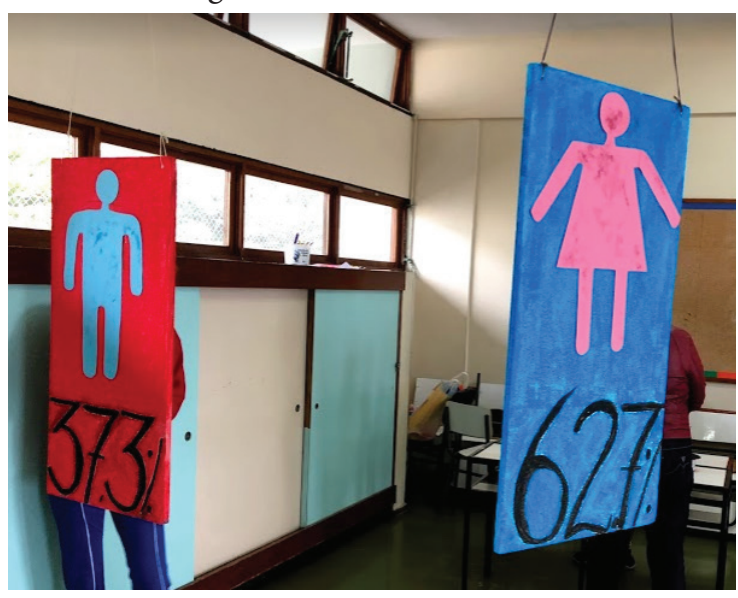

Fonte: acervo pessoal. 
Figura 3 - Módulo Estado Civil

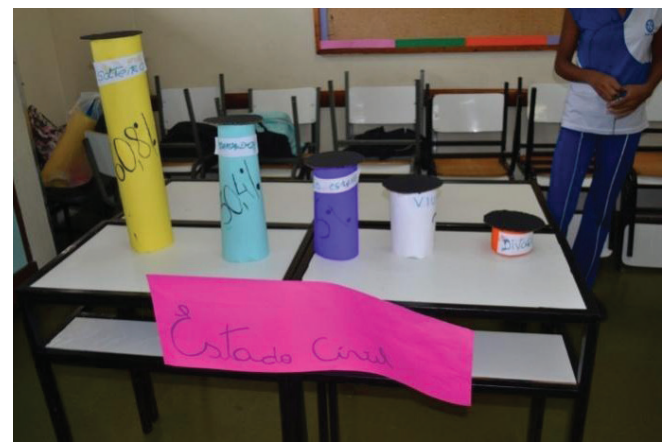

Fonte: acervo pessoal.

Figura 4 - Módulo Autodeclaração de Cor

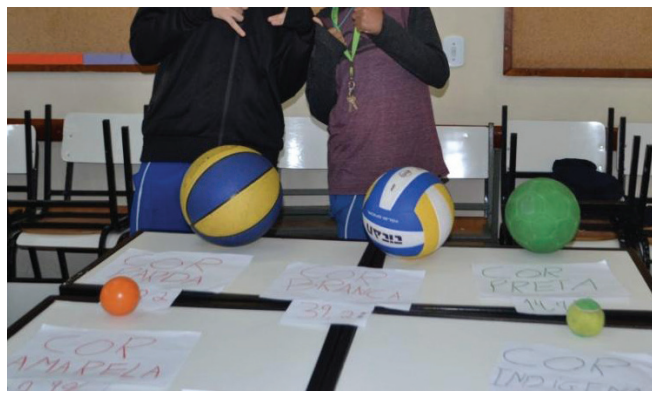

Fonte: acervo pessoal.

Figura 5 - Módulo Faixa Salarial

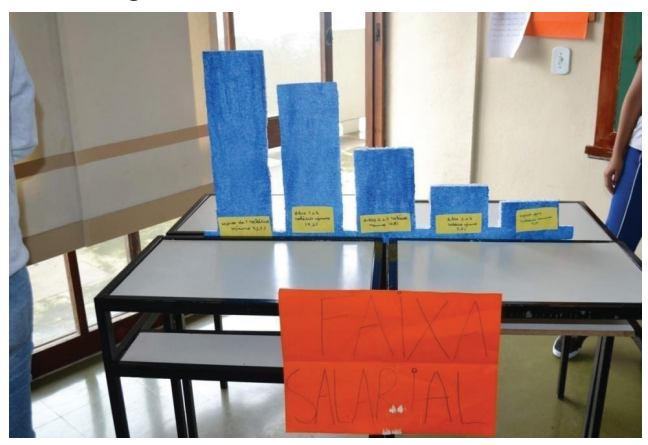

Fonte: acervo pessoal. 
Foi geralmente muito produtivo os alunos da turma ouvirem as dúvidas, inquietações e comentários dos visitantes sobre a temática do racismo no Vidigal. Para eles, a questão do racismo parecia muito distante da favela, por vezes naturalizada como uma prática "do asfalto", mas diante daqueles dados começava a ganhar novos contornos e passava a ser compreendida como uma prática muito presente no dia a dia dos moradores do Vidigal dentro da própria favela.

Nesse momento, a construção do conhecimento científico produzida pela escola ganhou um sentido dialógico com o cotidiano dos discentes, uma vez que o conhecimento ganhou um sentido prático, quando os moradores puderam se ver representados naqueles dados. Explicitou-se a relação entre os conteúdos dos componentes curriculares e o "mundo extramuros" da escola, dando sentido àquilo que é estudado e debatido nas disciplinas.

O último módulo da exposição trazia o impressionante número de $70 \%$ dos entrevistados relatando terem vivido ou presenciado alguma situação de racismo - muitas vezes dentro da própria favela, praticado pelos próprios moradores do Vidigal. Os relatos demonstraram casos bem específicos em que esse racismo se manifestou, como nas ocasiões em que jovens negros perceberam olhares de suspeição ao entrarem no transporte público, ou mesmo a abordagem policial violenta nas vielas da favela, e ainda, as dificuldades em se manterem nas instituições escolares diante do alto custo com deslocamento, material didático, alimentação e, por vezes, terem de escolher entre trabalhar para ajudar na renda familiar e/ou estudar.

\section{Avaliação}

Nas aulas que sucederam a Mostra Anual de Atividades foi necessário realizar a avaliação da atividade. Uma vez que a nota atribuída aos alunos após a exposição é utilizada pelos professores para compor a nota bimestral, optamos por realizar uma avaliação processual. Tal estratégia foi adotada de modo a nos permitir o acompanhamento constante e sistemático de todas as etapas do projeto apresentado. Buscamos, assim, que o processo de avaliação da aprendizagem dos alunos assumisse um caráter transformador e que estivesse comprometido com valores maiores que a "meritocracia" da nota, com a totalidade do aluno (Vasconcellos, 2005, p. 41). 
Após a avaliação processual, no passo seguinte solicitamos que os alunos se autoavaliassem, por acreditarmos nesse mecanismo da autonomia e da prática da autogestão do conhecimento como importantes formas de desenvolvimento da autonomia pessoal e de comprometimento com a atividade e com o processo educativo.

Num diálogo com os alunos, avaliamos o processo geral da Mostra de Atividades, o que cada um aprendeu com as apresentações, os comentários e as perguntas dos visitantes. Um aluno trouxe a afirmação de que a exposição organizada pela turma, exigindo de todos os alunos um comprometimento com a luta por uma sociedade mais justa, transformou a questão racial em prioridade na elaboração de iniciativas capazes de reparar ações desumanas ligadas à escravidão e ainda hoje tão presentes nas nossas vidas. É fundamental, então, que essa transformação comece nas escolas.

Uma aluna trouxe o questionamento de um visitante sobre os números apresentados, afirmando que o racismo no Vidigal com aquela quantidade de entrevistas não representava o pensamento da maioria dos moradores da favela. Segundo esse visitante, todos deveriam ser ouvidos para que, só assim, pudéssemos de fato chegar àquelas conclusões. Porém, ele não entendeu que a pesquisa representava uma amostragem e que, em muitos pontos, os dados confirmavam o panorama macro de pesquisas, como a do IBGE para a cidade e o país.

\section{CONSIDERAÇÕES FINAIS}

Neste artigo relatamos a preparação, o planejamento e a avaliação dos trabalhos realizados por uma turma de $8^{\circ}$ ano do Ensino Fundamental para a

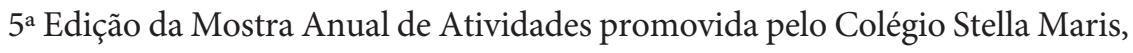
situado na favela carioca do Vidigal.

Constatamos, primeiramente, a dificuldade dos alunos em reconhecer o racismo como uma prática disseminada em seu cotidiano. Até mesmo a simples autodeclaração sobre a "Cor", seja dos alunos e/ou dos entrevistados, sinalizava a dificuldade que muitos ainda têm para se reconhecerem como parte dessa negritude e compreenderem os múltiplos valores dos negros e negras na nossa sociedade.

Entretanto, o resultado da atividade indicou aos educadores a importância da abordagem dos temas ligados à história da África e do Brasil Afrodescendente 
em nossas salas de aula. Antes de tudo porque somos responsáveis pelo cumprimento da Lei 10.639/03, que estabeleceu a obrigatoriedade do Ensino de História e Cultura Afro-Brasileira e Africana no currículo da Educação Básica, o que exige de todos nós, envolvidos no processo educacional, a promoção de uma educação igualitária racial em nossas salas de aula.

Negligenciar isso é negligenciar aos nossos alunos e alunas o direito de conhecer sua própria história e o direito de igualdade previsto na atual Constituição Brasileira. "Valorizar a história dos negros" não deve, portanto, ser visto como restrito à população negra; bem ao contrário disso, espera-se que todos os cidadãos, chamados brasileiros, tenham a capacidade de viver e construir uma sociedade democrática no sentido mais amplo. E como tal, vivenciem plenamente o ambiente democrático de uma sociedade multicultural e pluriétnica, que compreenda as diferenças entre privilégios e políticas de reparação.

O racismo é crime que deve ser combatido diariamente, e nunca deve ser naturalizado como "algo que não tem solução" - como afirmou um dos visitantes da Mostra de Atividades. Daí a importância de atividades capazes de promover o fortalecimento dos negros e que provoquem o despertar de uma vida não racista em brancos, para que a partir daí possamos forjar novas relações étnico-raciais comprometidas com a justiça racial.

\section{REFERÊNCIAS}

BERNSTEIN, Basil. Class, codes and control. London: Routledge and Kehgan Paul, 1980.

BRASIL. Instituto Brasileiro de Geografia e Estatística. Relatório do Comitê Nacional para a preparação da Participação Brasileira na III Conferência Mundial das Nações Unidas Contra o Racismo, Discriminação Racial, Xenofobia, e Intolerância Correlata. Brasília: IBGE, 2001. Disponível em: http://www.dhnet.org.br/direitos/ sos/discrim/relatorio.htm. Acesso em: 20 ago. 2018.

BRASIL. Instituto Brasileiro de Geografia e Estatística. Vamos Contar! Censo 2010 nas escolas. Guia do professor Ensino Fundamental. Rio de Janeiro: IBGE, 2010. Disponível em: https://ww2.ibge.gov.br/vamoscontar2010/guias_flipbook/guia_6_ ao_9.pdf. Acesso em: 9 dez. 2018.

FAZENDA, Ivani. Integração e interdisciplinaridade no ensino brasileiro: efetividade ou ideologia. São Paulo: Loyola, 1979. 
FREIRE, Paulo. Pedagogia da autonomia: saberes necessários à prática educativa. São Paulo: Paz e Terra, 1996.

FREIRE, Paulo. Pedagogia do oprimido. Rio de Janeiro: Paz e Terra, 1987.

GADOTTI, Moacir. Interdisciplinaridade: atitude e método. São Paulo: Instituto Paulo Freire, 1999.

GARRETÓN, Manuel. Cidadania, integração nacional e educação: ideologia e consenso na América Latina. In: ALBALA-BERTRAND, Luis (org.). Cidadania e educação: rumo a uma prática significativa. Campinas: Papirus, 1999.

GOMES, Nilma Lino. Diversidade étnico-racial, inclusão e equidade na educação brasileira: desafios, políticas e práticas. Revista Brasileira de Política e Administração da Educação (RBPAE), v. 27, n. 1, p. 109-121, jan./abr. 2011. Disponível em: https://seer.ufrgs.br/rbpae/article/view/19971/11602. Acesso em: 8 dez. 2018.

NUNES, Sylvia da Silveira. Racismo no Brasil: tentativas de disfarce de uma violência explícita. Psicologia USP, São Paulo, v. 17, n. 1, p. 89-98, 2006. Disponível em: http://www.scielo.br/scielo.php?script=sci_arttext\&pid=S0103-65642006000100007\&lng=en\&nrm=iso. Acesso em: 20 ago. 2018.

PETRUCCELLI, José Luis; SABOIA, Ana Lucia (org.). Características étnico-raciais da população: classificação e identidades. Rio de Janeiro: IBGE, 2013.

POMBO, Olga. Problemas e perspectivas da interdisciplinaridade. Revista de Educação, v. IV, p. 3-11, 1994.

SANTOS, Alessandro de O. dos; FERNANDES, Saulo Luders. A psicologia na compreensão étnico-racial do negro no Brasil. In: OLIVEIRA, Iolanda; PESSANHA, Marcia Maria de J. Educação e relações raciais. Niterói: Cead/UFF, 2016.

STELLA MARIS, Colégio. "Instituição", "Proposta Pedagógica”. S. d. Disponível em: http://www.stellamaris-rj.com.br/. Acesso em: 5 ago. 2018.

TAVARES, Celma. Educar em direitos humanos, o desafio da formação dos educadores numa perspectiva multidisciplinar. In: SILVEIRA, Rosa Maria G. et al. Educação em direitos humanos: fundamentos teórico-metodológicos. João Pessoa: Ed. Universitária, 2007.

TEPEDINO, Cristina de Azeredo L. Cotidiano escolar e mudança sociocultural: a experiência do Colégio Stella Maris. 2007. Dissertação (Mestrado em Educação) Pontifícia Universidade Católica do Rio de Janeiro (PUC Rio). Rio de Janeiro, 2007. Disponível em: https://www.maxwell.vrac.puc-rio.br/10741/10741_1.PDF. Acesso em: 12 ago. 2018.

VASCONCELLOS, Celso. Avaliação da aprendizagem: práticas de mudanças: por uma práxis transformadora. São Paulo: Libertad, 2005. 


\section{ANEXO I}

Nome: Idade:

Questão 1

\begin{tabular}{|l|l|}
\hline \multicolumn{2}{|c|}{ SEXO } \\
\hline MASCULINO & FEMININO \\
\hline
\end{tabular}

Questão 2

\begin{tabular}{|l|l|l|l|l|l|}
\hline \multicolumn{5}{|c|}{ QUAL A SUA RELIGIÃO? } \\
\hline CATÓLICO & EVANGÉLICO & KARDECISTA & UMBANDA & CANDOMBLÉ & OUTRA \\
\hline
\end{tabular}

Questão 3

\begin{tabular}{|l|c|c|c|c|}
\hline \multicolumn{5}{|c|}{ RAÇA OU COR SEGUNDO O IBGE ? } \\
\hline BRANCA & PRETA & PARDA & AMARELA & INDÍGENA \\
\hline
\end{tabular}

Questão 4

\begin{tabular}{|c|c|c|c|c|}
\hline \multicolumn{5}{|c|}{ QUAL SEU ESTADO SOLTEIRO } \\
\hline SOLTEIRO & CASADO & UNIÃO ESTÁVEL & VIÚVO & DIVORCIADO \\
\hline
\end{tabular}

Questão 5

\begin{tabular}{|c|c|c|}
\hline \multicolumn{3}{|c|}{ NÍVEL DE ESCOLARIDADE } \\
\hline $1^{\circ} \mathrm{EF}$ & $2^{\circ} \mathrm{EF}$ & $3^{\circ} \mathrm{EF}$ \\
\hline $4^{\circ} \mathrm{EF}$ & $5^{\circ} \mathrm{EF}$ & $6^{\circ} \mathrm{EF}$ \\
\hline $7^{\circ} \mathrm{EF}$ & $8^{\circ} \mathrm{EF}$ & $9^{\circ} \mathrm{EF}$ \\
\hline $1^{\circ} \mathrm{EM}$ & $2^{\circ} \mathrm{EM}$ & $3^{\circ} \mathrm{EM}$ \\
\hline Superior incompleto & Superior completo & Não alfabetizado \\
\hline
\end{tabular}

Questão 6

\begin{tabular}{|c|}
\hline OCUPAÇÃO \\
\hline \\
\hline
\end{tabular}

\section{Questão 7}

\begin{tabular}{|c|c|c|c|c|}
\hline \multicolumn{5}{|c|}{ FAIXA SALARIAL INDIVIDUAL } \\
\hline MENOS DE 1 SM & ENTRE 1 E 2 SM & ENTRE 2 E 3 SM & ENTRE 3 A 4 SM & MAIS DE 4 SM \\
\hline
\end{tabular}

\section{Questão 8}

\begin{tabular}{|c|c|}
\hline \multicolumn{2}{|c|}{ EXISTE RACISMO NO VIDIGAL? } \\
\hline SIM & NÃO \\
\hline
\end{tabular}

\section{Questão 9}

VOCÊ JÁ SOFREU OU PRESENCIOU ALGUMA DISCRIMINAÇÃO RACIAL? SE SIM, COMENTE.

\begin{tabular}{l|l} 
SIM & NÃO \\
\hline
\end{tabular}




\section{NOTAS}

${ }^{1}$ Os números são de agosto de 2018.

${ }^{2}$ Sobre a Campanha da Fraternidade 2018 promovida pela CNBB ver o texto "Reflexão sobre o tema da Campanha da Fraternidade 2018 Superação da Violência" Disponível em: http://www.cnbb.org.br/reflexao-sobre-o-tema-da-campanha-da-fraternidade-2018-superacao-da-violencia/. Acesso em: 5 ago. 2018.

${ }^{3}$ IBGE. "Estatísticas de Gênero mostram como as mulheres vêm ganhando espaço na realidade socioeconômica do país". Disponível em: https://censo2010.ibge.gov.br/noticias-cen so busca $=1 \& \mathrm{id}=1 \& \mathrm{idnoticia}=2747 \& \mathrm{t}=$ estatisticas- genero-mostram-como-mulheres -vem-ganhando-espaco-realidade-socioeconomica-pais\&view=noticia.

${ }^{4}$ Um panorama da pesquisa nacional realizada pelo IBGE está disponível em: https://cidades.ibge.gov.br/brasil/rj/rio-de-janeiro/panorama. Acesso em: 12 ago. 2018.

${ }^{5}$ Dados disponíveis em: https://agenciadenoticias.ibge.gov.br/agencia-noticias/2012-agencia-de-noticias/noticias/21206-ibge-mostra-as-cores-da-desigualdade. Acesso em: 20 ago. 2018.

Artigo recebido em 8 de outubro de 2018. Aprovado em 29 de janeiro de 2019. 